\title{
Wall of Prostatic Duct
}

National Cancer Institute

\section{Source}

National Cancer Institute. Wall of Prostatic Duct. NCI Thesaurus. Code C13107.

A layer of epithelium comprising both columnar and small cuboidal cells. 